\title{
Coping with IT! Antecedents and Consequences of Technostress in E-Commerce
}

\author{
Leonore Peters \\ University of Bamberg \\ leonore.peters@uni-bamberg.de
}

\author{
Jasmin Feste \\ University of Bamberg \\ jasmin.feste@uni-bamberg.de
}

\author{
Katharina Schumacher \\ katharinaschumacher@hotmail.de
}

\begin{abstract}
Technostress represents a high risk for e-commerce operators as consumers perceiving technostress are likely to leave online stores without making a purchase. However, research on technostress mechanisms in ecommerce is scarce. Conducting an online betweensubjects experiment, we aim to address these research gaps by providing insights on when technostress arises in an e-commerce context, which coping strategies consumers apply when perceiving technostress and how this affects their behavior: We empirically investigate which technology-induced stressors create technostress in an online store and how they affect purchase intention. Our moderated mediation analysis based on 160 respondents reveals a negative indirect effect of technostress on consumers' purchasing intention, mediated by consumers' perception of website quality, website trust, and choice of coping strategy. Thereby, we contribute to technostress, coping and e-commerce literature and extend research by presenting empirically validated technology-induced stressors together with insights into the mechanism of a transactional technostress-model in the context of e-commerce.
\end{abstract}

\section{Introduction}

We know from consumer psychology studies that some people go shopping when they experience stress in their lives. There is much evidence suggesting that shopping and the associated spending of money is a coping strategy to reduce stress occurring from other areas of life $[1,2]$. Nowadays, you can even satisfy this need spontaneously due to a high supply of online stores and offers. But, what if you then shop online and also experience stress, which is triggered by the technology used and thus independent of the actual stress?

We still know very little about how consumers cope with stress they experience while shopping online. Especially in e-commerce literature, studies on consumption behavior and coping behavior under stress are scarce. This is surprising, since in e-commerce it is even easier to end the perceived stress by just clicking the closing button than when you are in a shopping mall. Findings from e-commerce-research undermine the importance of website usability and a high-quality website appearance, due to their effect on consumers' purchase behavior [e.g. 3, 4, 5, 6]. However, we have to take into account that these normal mechanisms do not necessarily take place because individuals under stress evaluate situations differently, which indirectly affects consumer reactions $[7,8,9]$.

From an e-commerce operator perspective it is therefore crucial to understand how and when the perception of technological stress, that is, stress perceived while using information and communication technologies (ICTs), arises [10]. Considering the shortterm nature of online shopping and the strong competition in e-commerce, it is primarily the situational evaluation of stress that is of interest. Consequently, this also applies to the way consumers' deal with stress. Therefore, we assume that situational technological stress, the evaluation of it and the way of coping with it are decisive for whether consumers make a purchase decision or not in that particular situation.

The transactional stress model describes the process of experiencing and acting upon a stressful event, starting from the induction of stressors, through the evaluation of the situation and potential coping strategies, and the final re-evaluation of the situation and therefore provides the theoretical framework for our study $[7,8]$. While several studies in the technostressliterature build on the model by Lazarus and Folkman, only few take the whole process into consideration and only few transfer the model to a non-organizational context. There is a vast body of research on technologyinduced stressors in an organizational context. Nevertheless, several researchers clearly point out that these stressors would be different in other contexts, such as online shopping [11]. Moreover, it seems that research on coping strategies in general is underrepresented in the technostress literature [exceptions include 12, 13] and in the e-commerce literature in particular [exceptions include 14, 15]. We therefore answer the call for research from Pirkkalainen 
et al. (2019) and Tarafdar et al. (2019) [11, 13] and provide insights on the effect of certain coping strategies in an online shopping context. Previous studies indicate that compared to a work-context, different aspects of the evaluation of the situation and also to the outcomes in an e-commerce setting need to be analyzed [11]. Consequently, we aim to close this research gap and empirically and conceptually contribute to both ecommerce and technostress literature. We empirically investigate which technology-induced stressors are applicable in an e-commerce context and how they indirectly affect consumers' intention to purchase from the website, mediated by the evaluation of the online shopping situation, i.e. perceived website quality and perceived trust in a website, and choice of coping strategy. We explore this process in an experimental setting.

The remainder of this paper is as follows. First, we provide a theoretical framework based on the transactional stress theory, and outline the concept of technostress and user experience in e-commerce. On this basis, we present our research model and derive four research hypotheses. Subsequently, we present the experimental design of our study and analyze research results. Finally, we discuss our contributions to research and practice and conclude with limitations of our study and avenues for further research.

\section{Theoretical Foundation and Research Model}

\subsection{Transactional Stress Theory and Coping Strategies}

The cognitive transactional stress-model considers stress states as multi-layered transactional processes between demands of a situation and the individual person experiencing and acting in that situation. Lazarus and Folkman (1984) describe different evaluation process phases, which an individual undergoes. During

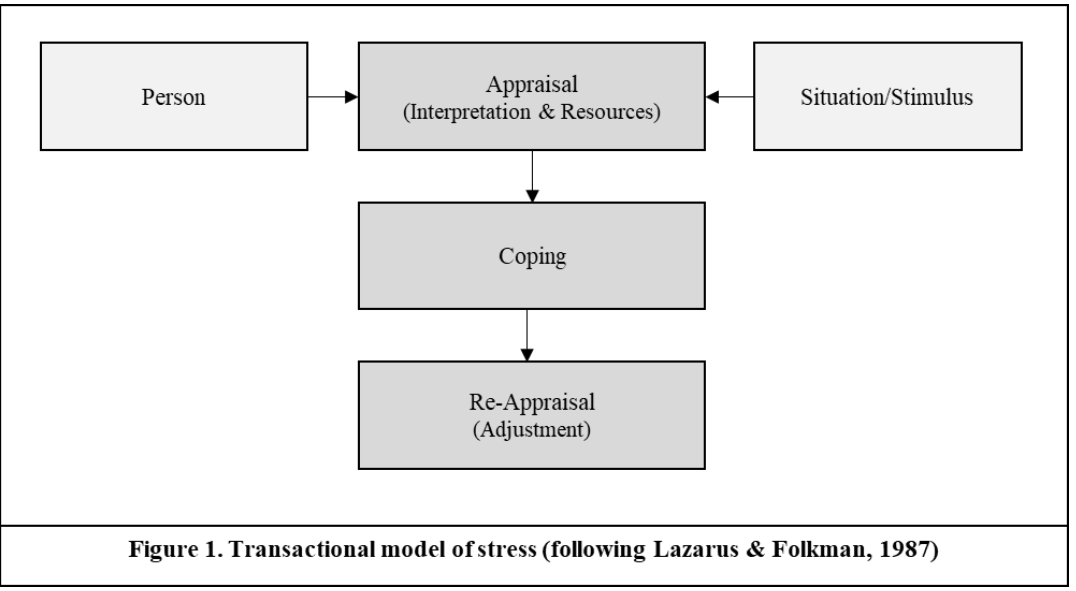

appraisal process phases, individuals evaluate the situation and whether stressors are identified as threatening factors. In a next step, individuals employ different coping strategies and responses to occurring stress, which help to overcome the effect of certain stressors. In a final phase - re-appraisal - individuals reevaluate the situation according to whether stress has been managed successfully [7,8]. When individuals conclude that stress has not been successfully managed, several effects result. Stress occurs on both a physical and a psychological level $[7,16]$. Physical responses can be measured by an increase in cortisol levels or blood pressure. Besides, they are expressed by increased muscle tension or perspiration. Psychological stress results from an individual's appraisal of situational factors, which can trigger feelings of being overwhelmed, states like anxiety, anger, and yielding insufficient resources to cope with the situation $[7,9,14$, $16,17,18,19]$.

The transactional stress model suggests individuals applying coping strategies for reacting to perceived stress. Coping efforts are undertaken to better manage external or internal demands [7,8]. Coping strategies are process-oriented. Individuals apply different coping strategies depending on differing demands and contexts of the situation $[7,8,20]$.

Two main coping styles are identified by literature, creating the overarching frame for specific coping strategies. Proactive coping is problem-based and focused on and targeted to change the source of stress or the conditions of the stressor(s). It describes efforts aiming at eliminating or diminishing the influence of the source of stress. For instance, a stressed consumer in front of a purchase decision could search for additional information to reduce feelings of uncertainty. On the contrary, a reactive coping strategy does not focus on the stressor itself, but is guided by the motivation to return to an unstressed context. Individuals therefore are not handling stress by addressing it but rather by ignoring or refusing the respective stressful situation [7, $12,13,15,20,21]$. Figure 1 represents a simplified visualization of the transactional model of stress following Lazarus and Folkman (1987) [8].

\subsection{Technostress and User Experience in E-Commerce}

Due to the indisputable relevance and power of online shops, there is a strong global competition for market share. Online shopping platforms therefore have to gain understanding of consumer motives for making a 
purchase decision and further increase knowledge about the buying process and consumer evaluations in order to improve customer experience [17]. Research identifies quality of the product, website quality and trust $[3,4,22$, $23,24]$ as main influencers for an online buying decision. These evaluations are positively associated with making a purchase decision in an online shop. However, consumers experience uncertainties and doubts that hold them back from making a decision. From research in stationary shops, we know that the buying process itself is exhausting for consumers in many ways. This includes stress resulting from product failures or consumer uncertainty for making the right decision [15, 25, 26, 27]. These aspects become even more relevant in the technological environment of an online store. Consumers face an anonymous setting, have concerns regarding information security and compliance, and are regularly confronted with new features and applications. As a result, users of ICTs and consumers feel overwhelmed, frustrated and insecure feelings that can lead to stress $[9,14,28,29]$.

Stress arising in the context of information and communication technology is referred to as technostress. Ragu-Nathan et al. (2008) define technostress as "phenomenon of stress experienced by end users in organizations as a result of their use of ICTs" [10]. This definition encompasses the use of ICTs, adopting and learning to deal with new technologies, as well as using and modifying existing ICTs $[10,13,30]$. Rapid changes in technology and the required demand for cognitive and physical abilities of its users can lead to stress-inducing conditions [29]. Technostress research in an organizational context reveals five different technostress creators: technooverload, techno-invasion, techno-complexity, technoinsecurity and techno-uncertainty. This conceptualization has proven itself in the work context and is widely recognized [e.g. 10, 31, 32]. According to the adapted stress-model by Tarafdar et al. (2007) [31], these stressors lead to the perception of stress, which is manifested in the following outcomes: (1) ICTs usagerelated outcomes, i.e. dissatisfaction with ICTs, low perception of support of ICTs and (2) general jobrelated outcomes, i.e. decrease of job satisfaction, productivity, commitment to the organization, individuals well-being, job control, and increase in role stress, anxiety and boredom [10, 29, 31, 33, 34]. Nevertheless, it is important to emphasize that these stressors are not transferable one-to-one to other areas of life.

Extensive research is performed on technostress in the work context [e.g. 10, 21, 29, 31, 33, 35], whereas the non-work contexts of individuals' lives remain under-researched $[11,36]$. Exceptions include research on technostress and social media usage [e.g. 37, 38, 39,
$40,41]$, technostress in innovation processes [30, 42] and technostress in online shopping contexts $[9,14,17]$. Tarafdar et al. (2019) suggest that the technostress sources and effects in an online shopping context could be different and would need to be adapted [11]. Riedl et al. (2012) divide sources of stress into acute (website functionality, information overload) and chronic stressors (IT security requirements) and analyze the effects of technostress from a neurobiological perspective. Their neurobiological experimental study shows that technostress, induced by system breakdowns, has a significant effect on the formation of cortisol - an important stress hormone influencing blood pressure [9]. Moody and Galletta (2015) add to this research by providing evidence for information scent as a stressor in e-commerce. Further, they demonstrate that perceived stress has a significant negative influence on attitudes towards a website [17]. Chen et al. (2019) confirm their findings with regard to the information aspect and analyze information overload and perceived intrusiveness as stressors, operationalized as push notifications from mobile applications. Their results show that these stressors partially influence coping with perceived stress. Specifically, the results show an influence of coping strategies on discontinuance behavior [14]. Their study provides valuable insights on private user behavior of ICTs. However, the online shopping experience is largely neglected. The authors focus only on the aspect associated with information overload and intrusive behavior as a stressor [14]. Further research on technology-induced stressors, perceived technostress in e-commerce and the effect on consumer attitudes and behavior is necessary.

\subsection{Research Model}

Research on technostress in e-commerce is scarce and furthermore does not yet address the stress process to its full extent. Responding to the call for research by Tarafdar et al. (2019) and Grummeeck-Braamt et al. (2021) [11,43], we investigate which stressors occur in an e-commerce context and analyze their effects. Drawing on the transactional stress model, we suggest an effect of technology-induced stressors on the evaluation of situational factors - i.e. perception of website quality and resulting website trust - that can trigger feelings of being overwhelmed and influence the choice of respective coping strategies. Depending on the coping strategy chosen, we expect different effects on purchase intention - which represents the goal consumers pursue when "entering" an online store.

According to the stress model, in a first step individuals evaluate the situation in an online shop, whether the appearance of a website is normal and whether factors are recognized that prevent the 
achievement of the goal to make a purchase. A key attribute for evaluating an online shop is perceived website quality $[3,5,6,44]$. The website of an online store is, in a way, a substitute for a physical store. In physical stores, a lot of attention is paid to equipment, layout, appearance of employees, etc. These attributes determine whether consumers will visit the store and whether consumers rate the store as high quality. In online stores, the design of the website compensates for this [45]. Technology-induced stressors, such as poor functionality, loading images, and distracting advertising or pop-ups highly irritate consumers $[5,9$, 17, 44, 46]. Therefore, we expect that technologyinduced stressors influence the situation in an online store in such way that consumers perceive the situation as abnormal and consequently perceive the website quality as low:

Hypothesis 1: Technostress has a negative impact on the perceived website quality.

Research on website design and website usability is in broad agreement on the relationship of website quality and website trust. There is a vast body of research that considers website quality as antecedent of trust in a website [e.g. 3, 5, 47]. The evaluation of the website quality of an online store is the substitute for the evaluation of physically existing attributes. In stationary stores, these are crucial for developing a sense of trust. The absence of physical sales representatives and other tangible cues highlights the importance of trust [48]. Website quality serves as a cue for consumers to evaluate whether the website is accurate and competent. When these expectations are met and consumers are confident that the e-commerce operator and the website is reliable, they create a feeling of trust [22, 49, 50]. In line with this research, we posit the following:

\section{Hypothesis 2: Perceived website quality has a positive effect on perceived trust in a website.}

Research on the stress model by Lazarus and Folkman (1984) shows evidence for coping strategy as a mediating factor between the appraisal phase and the outcome $[7,51,52]$. The cognitive and emotional evaluation of the situation has a significant influence on the strategy consumers choose to overcome the stressful situation $[7,8,16]$. Trust in a website is crucial to whether a consumer feels safe on the website or perceives risk and feels insecurity. When trust in the website is low, strong uncertainty acts as a stress factor in the situation [44]. As a result, consumers are not well able to cope with the demands of the situation. They lose sight of the goal and do not want to deal with the buying process any further. This reflects the behavior of a reactive coping strategy [30]. Consumers are guided by the desire to leave the situation as quickly as possible and return to an unstressed state. The reactive coping style is expressed by consumers ignoring or rejecting the situation. When trust in the website is high, we expect the corresponding opposite effect to occur. Consumers are confident to cope with potential uncertainties and apply a proactive coping strategy. The proactive coping strategy is expressed by the motivation to search for additional information in order to reduce or eliminate perceived stress [7, 15, 20, 21]. Accordingly, we propose the following:

Hypothesis 3: Perceived trust in a website has an effect on the chosen coping strategy. Low trust results in reactive coping, whereas high trust results in proactive coping.

Drawing on coping research, we elaborated the effect of different coping strategies on the outcome of a situation. In an e-commerce context, consumers pursue the goal of making a purchase. The way consumers deal with stress has a direct effect on the achievement of this goal [30]. When we compare the two coping styles, we expect contrary effects on purchase intention. A reactive coping style leads consumers to want to leave the situation as quickly as possible. Consumers are thus no longer driven by the goal of making a purchase, but instead by the desire to remove the stress. This is then subsequently expressed in the fact that the purchase intention is low. In a proactive coping style, customers continue to pursue the goal of making a purchase. Due to the additional search for information or testing of products, the purchase intention is therefore high [13, $30,49,52,53]$.

Hypothesis 4: The chosen coping strategy has an effect on intention to purchase on the website. Reactive coping influences purchase intention negatively, whereas proactive coping has a positive impact on purchase intention.

\section{Empirical Study}

\subsection{Experimental Design and Participants}

We conducted a between-subjects experimental study to assess the effect of technostress on peoples' intention to purchase through the mediators website quality, website trust, and coping mechanisms. Applying an experimental research design, it is possible to investigate the assumed causal relationships. Thus, among all available research methods, the experimental design is considered the strongest when it comes to 


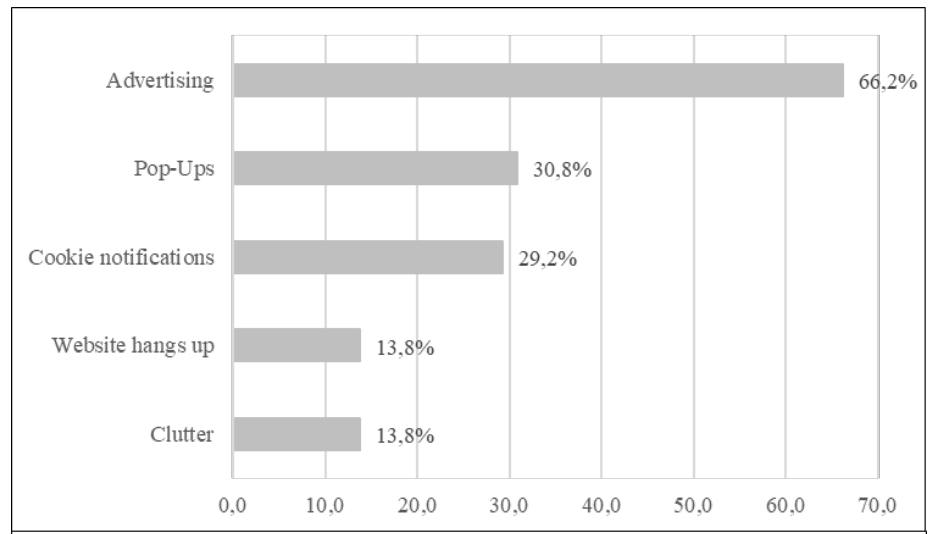

Figure 2. Stress factors in online shopping

investigating causal relationships between variables [54, 55].

We recruited participants applying a snowball technique, starting with acquaintances, friends and family members of undergraduate and graduate students of a German university. Thus, a link to the online questionnaire on the research platform "Unipark" was shared. Our sample represents a spectrum of demographic and socio-economic groups and thus, provides an adequate sample of consumer groups in Germany.

160 participants took part in the experiment. Approximately $56 \%$ of the sample is female. The mean age is 37.3 years $(\mathrm{SD}=15.1)$. The youngest participant was 19 , whereas the oldest was 73 years old. With this age distribution, our sample covers the most relevant age groups of online shoppers in Germany, as $77 \%$ of 16 to 24 year olds, $90 \%$ of 25 to 44 year olds and $76 \%$ of 45 to 64 year olds were online shoppers in 2020 [56].

The online questionnaire exposed participants randomly to one of the two website designs (technostress manipulation vs. no technostress manipulation), so that age and gender are equally distributed across both conditions.

\subsection{Stimulus and Procedure}

To investigate our research hypotheses, we created two fictional German online stores providing ordinary food supplies. Their overall design was oriented towards the regular style of online stores. The only distinction between the two websites was the explicit manipulation of technostress on one website, applying several techno stressors. The basis for our manipulative technostress design was twofold. First, prior to our main study, we conducted an exploratory survey with 65 students at a German university to find out what they consider to be stress factors when they want to make a purchase in an online store. Figure 2 gives an overview of the five most frequently mentioned stressors, that are, advertising, pop-ups, cookie notifications, website hang-ups, and clutter.

Subsequently, we visualized these stressors in a regular online shopping scenario. Second, we pretested which arrangement of visualized stressor elicited the highest level of technostress in approximately 30 respondents per group, so we tested a wide variety of combinations that differed in number of stressors and their order. Figure 3 summarizes all tested combinations of techno stressors and their achieved mean values of respondents' perceived technostress. Concluding, we used the technostress manipulation of the third pretest for the technostress manipulation in our main study, which is visualized in detail in figure 4.

In our main study, we created an imaginary frame for the participants who took part in the experiment by encouraging them to view the website pictures carefully and to put themselves in the situation that they are about to buy food in an online store. In the following,

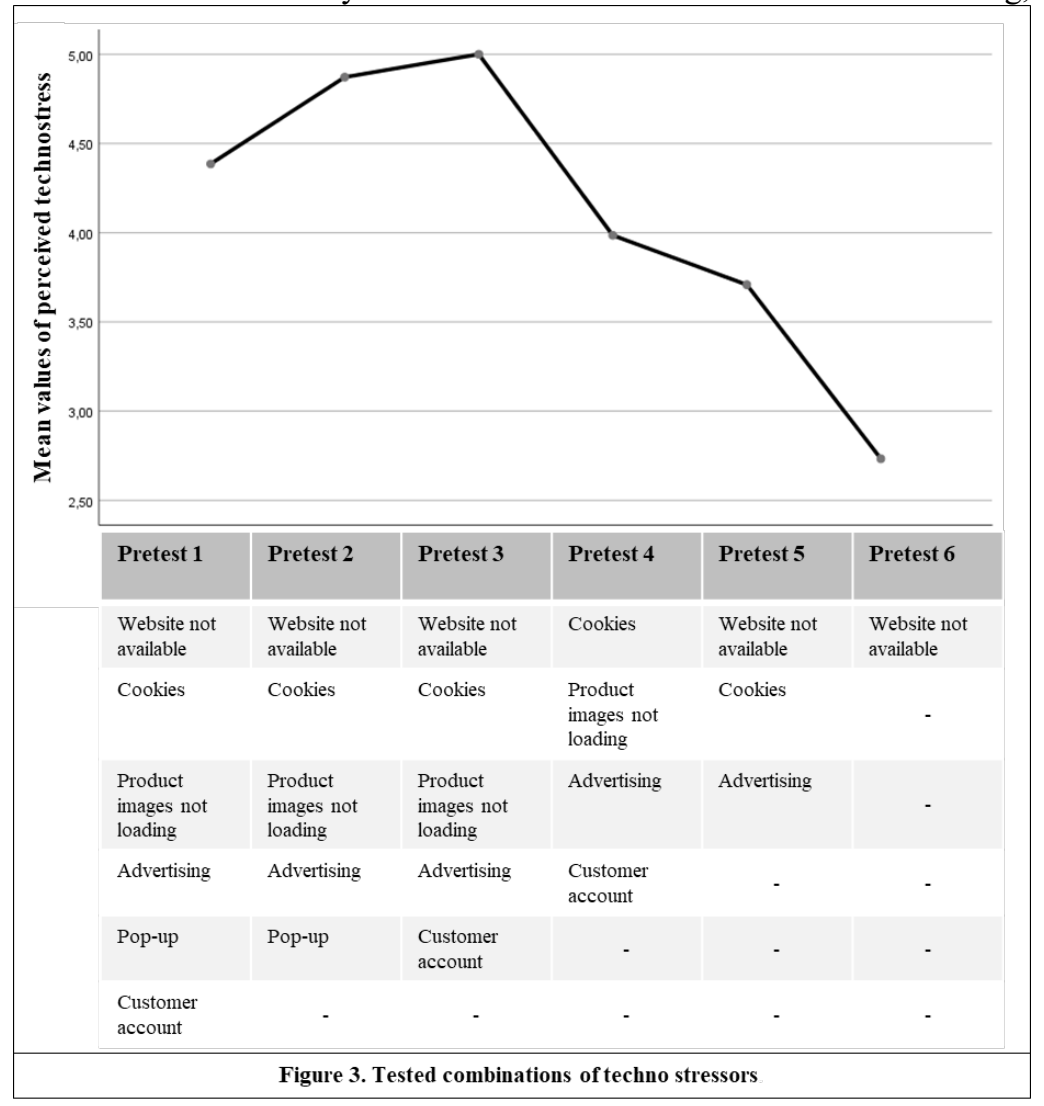




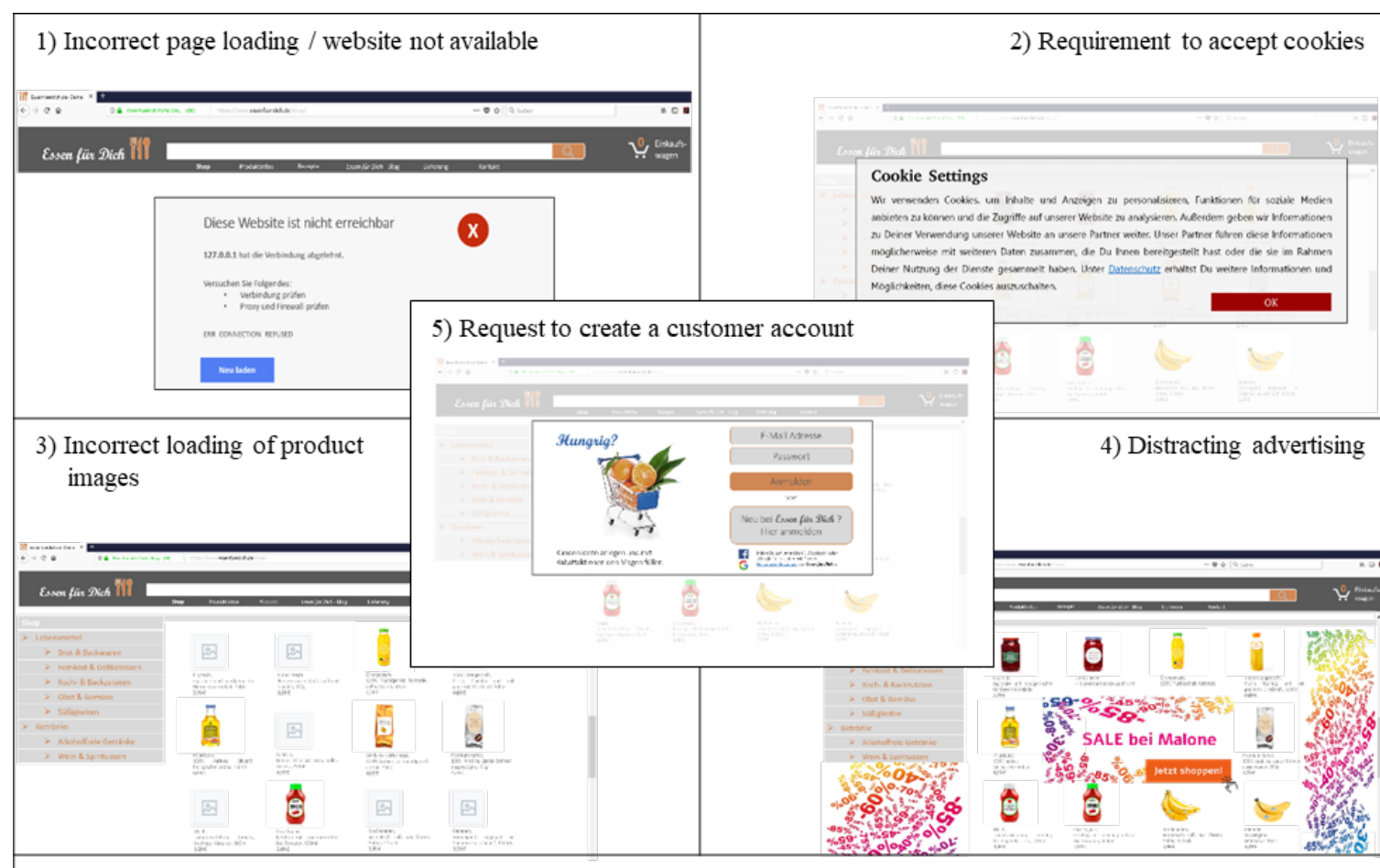

Figure 4. Technostress manipulation (experimental group)

participants answered questions about their impressions of the online store and their intention to purchase.

\subsection{Construct Measures and Manipulation Checks}

To measure the constructs of interest, we relied upon scales developed and validated in multiple previous studies. We used four items to measure respondents' perception of website quality [3], four items to measure visitors' overall trust in an online store [24], and three items to capture respondents' intention to purchase in an online store [3]. Coping of respondents was measured using a semantic differential variable with lower values representing proactive coping behavior and higher values representing reactive coping behavior. Respondents were asked to select one of the four coping strategies (strong proactive coping, weaker proactive coping, weaker reactive coping, and strong reactive coping) that reflects their reaction to the presented online shopping situation most accurately.

We established the measurement model by using CFA and by assessing global fit indices and criteria for the internal structure of the model [57, 58]. Results for the evaluation of the overall model fit using multiple indices show that all thresholds are met $(\chi 2 / \mathrm{df}=2.46 ; \mathrm{CFI}=0.97 ; \mathrm{TLI}=0.96 ; \mathrm{RMSEA}=$ 0.09 ; SRMR $=0.04)$, which points to an acceptable overall model fit. Furthermore, local fit parameters show evidence of the validity and reliability of the construct measures. Cronbach's alpha ranges between 0.92 and 0.97 , thus exceeding the commonly accepted threshold of 0.7 [59]. Average variance extracted (AVE) ranges between 0.77 and 0.89 , thus exceeding the threshold of 0.50 . Composite reliability (CR) ranges

\begin{tabular}{|c|}
\hline Table 1. Information on Construct Measures \\
\hline Website Quality (AVE $=0.77 ; \mathrm{CR}=0.92 ; \alpha=0.92)$ \\
\hline $\begin{array}{l}\text { 7-point Likert-type agreement scale ranging from } 1 \text { "Don't agree at all" to } 7 \text { "Fully agree" } \\
\text { - The website is of high quality. } \\
\text { - Probably the quality of the website is very high. } \\
\text { - The website must be of very good quality. } \\
\text { - The website seems to be of poor quality (R). }\end{array}$ \\
\hline Overall Trust in Online Store $(\mathrm{AVE}=0.89 ; \mathrm{CR}=0.97 ; \alpha=0.97)$ \\
\hline $\begin{array}{l}\text { 7-point Likert-type agreement scale ranging from } 1 \text { "Don't agree at all" to } 7 \text { "Fully agree" } \\
\text { - I would trust this online store. } \\
\text { - I think this online store is trustworthy. } \\
\text { - I consider this online store to be reliable. } \\
\text { - I appreciate the trustworthiness of this online store. }\end{array}$ \\
\hline Intention to Purchase from Online Store $(\mathrm{AVE}=0.83 ; \mathrm{CR}=0.94 ; \alpha=0.93$ ) \\
\hline $\begin{array}{l}\text { 7-point Likert-type agreement scale ranging from } 1 \text { "Don't agree at all" to } 7 \text { "Fully agree" } \\
\text { If I were to want to buy the products shown in the near future, ... } \\
\text { - } \quad \text {...I would consider buying from this site. } \\
\text { - ...I would buy them on this site. } \\
\text { - } \quad \text {...I could imagine buying on this site. }\end{array}$ \\
\hline Notes: $\alpha=$ Cronbach's alpha; $\mathrm{CR}=$ composite reliability; $\mathrm{AVE}=$ average variance extracted \\
\hline
\end{tabular}


between 0.93 and 0.97 , thus exceeding the threshold of 0.60 [57]. The highest squared correlation between the constructs is 0.63 , so that all AVE values for each construct are larger than the squared correlation between any pair of constructs, indicating discriminant validity [60]. Table 1 provides information on the measurement instruments for each construct and on their reliability and validity criteria. We surveyed respondents' perception of technostress using three items, which are, "The scenario shown personally would put me under a lot of stress", "My stress level in such an online shopping situation would be very high", and "I would perceive the online shopping situations shown as very stressful". A two sample t-test indicated a significant difference $\left(\mathrm{t}(158)=11.49, \mathrm{p}<0.001 ; \mathrm{M}_{\mathrm{techno}}=4.96, \mathrm{M}_{\mathrm{no}}\right.$ techno $=2.46$ ), thus pointing to a successful manipulation of technostress.

\subsection{Results}

We analyzed the postulated research model with a conditional process analysis based on a regression approach. We tested whether technostress translates into decreased intention to purchase from that website and whether this effect is mediated by website quality, website trust and coping. All multi-item constructs were combined into average scores.

In order to examine the conditional process model, we conducted a sequential mediation analysis using the SPSS macro PROCESS v3.5.3 [61]. We used Hayes' (2018) model six and entered the technostress experimental condition variable $(1=$ technostress manipulation) as independent variable, intention to purchase from that online store as dependent variable and website quality, website trust and coping as mediators. To test the indirect effect of technostress on intention to purchase from that online store, we used a bootstrapping approach [62] based on 5,000 bootstrap samples and calculated $95 \%$ bias-corrected confidence intervals (CI).

Hypothesis 1 predicts that technostress lowers peoples' perception of website quality. Results from the regression analysis show that technostress significantly affects the perception of website quality $(b=-1.19, p<$ 0.001 ), thus supporting hypothesis 1 .

Our second hypothesis assumes that perceived website quality positively influences peoples' perceived trust in that website. Analysis again reveals a highly significant effect $(b=0.76, p<0.001)$. Consequently, a higher perceived quality also increases the perceived trust in that website.

With hypothesis 3 we presume that a higher level of perceived trust in a website strengthens peoples' proactive coping behavior (confrontative coping) in contrast to reactive coping (avoidance coping). Also for this hypothesis, our analysis results show a significant negative effect $(b=-0.21, p<0.05)$, thus supporting our assumption.

Hypothesis 4 predicts that proactive coping behavior is more likely to lead to a higher intention to purchase from that online store than reactive coping does. Analysis supports our hypothesis as we receive a significant negative effect $(b=-0.17, p<0.05)$, meaning the stronger a person shows reactive coping, the lower its purchasing intention from that website, while the stronger preference for proactive coping leads to an increased purchase intention

Adding to described direct effects in our research model, we also probed the total indirect effect drawing on a bootstrapping approach. We achieve a significant negative total indirect effect $(b=-1.17$; CI $[-1.58$; $0.80]$ ). Consequently, technostress has a negative effect on peoples' purchasing intentions through the mediators website quality, website trust and coping, providing confirmation for our total research model.

\section{Discussion}

The findings from our experimental study provide important contributions to academic research. First, our results contribute to a deeper understanding of the effects of technostress in the online shopping context. We therefore add to the under-researched area of consumers' technostress perceptions and their resulting behavior on an online shopping website. We show that technostress leads to lower perceived website quality and website trust which results in a lower purchasing intention of consumers. In line with this, our research extends the technostress and coping literature, as we transfer existing research from an organizational context to an online shopping context [12,63]. Our study differentiates between two important mechanisms of technostress relief, i.e. proactive vs. reactive coping. In the course of this, our research contributes to a deeper understanding of the question on "why" negative consequences of technostress arise by showing that reactive coping in particular leads to reduced purchase intention in the online shopping context.

Moreover, our between-subjects experimental study design provides a suitable starting point for further research to achieve a comprehensive manipulation of technostress in the online shopping context, which was tested for validity in a rigorous pretest. Accordingly, we follow the research call to study techno stressors in the online context, as these are considered to be distinct from those in the work context [11]. Our technostress manipulation further provides important starting points for management practice. For example, while some stressors cannot be directly influenced by the retailer, such as the correct loading of a web page or of product 
images, some stressors, such as creating a customer account, are subject to the direct decision-making power of the retailers. Due to the serious effect of technostress, it is therefore advisable for retailers to actively avoid as many technology-induced stressors as possible. Similarly, cookie requests should be designed in such a way that the site visitor can easily either give full consent or set a personal cookie preference to avoid unnecessary technostress.

Despite the substantial contributions made, there is a need for further research nevertheless, as our study faces certain limitations. First, the present research considered only one specific product category in its manipulation of technostress, namely food supplies. This choice of product category was made to show products that have relevance to everyone in the survey and thus eliminate distorting effects on purchase intention due to the irrelevance of the products to the respondents. However, it is expected that different effects could arise depending on the product category offered. For example, offering wellness trips could have a technostress-reducing effect on respondents, which is likely to have different, if not positive, effects on purchase intention under technostress. We also did not control for the importance of the product for respondents, but it is to be expected that products with high importance for respondents, i.e. they absolutely need it and it is not available in other stores, will be purchased despite perceived technostress.

Second, our study did not consider the individual's experience with stress and personal individual characteristics. Instead, we included coping with stress solely on the basis of the coping strategy chosen. However, further research should include the consumer personality, e.g., by assessing the big five personality dimensions, which are expected to be related with the anticipation of certain coping mechanisms. Initial approaches to this are already discernible in studies in stationary stores [15]. Adding to this, we did not include individual traits of respondents, such as stressproneness, IT control or impatience $[63,64]$. In line with this, our results cannot be fully generalized either, as the sample is based on a random sampling approach and not on a quota sampling process that could depict all age groups of online shoppers in a representative way for a specific country or region.

Third, the pretest of the technostress manipulation was based on a student sample and thus covers a rather younger, but nevertheless important age group in the context of online shopping. Subsequent studies should thus be used to validate the presented technostress manipulation by including a broader age distribution. Further validation of the presented technostress manipulation would further test whether an imaginary purchase situation without actual risk is sufficient to trigger technostress in the participants of the experiment.

Furthermore, our study does not present additional means for intervention to reduce or even overcome perceptions of technostress. Information system literature already provides an interesting approach discussing the use of so-called avatars or humanized entities $[65,66,67]$. Studies on the implementation of avatars on online shopping websites widely agree that avatars can compensate for the lack of sales persons in virtual environments, thus increasing sociality in anonymous e-commerce settings [68, 69]. Further research should therefore investigate the extent to which avatars, with regard to their adding sociality, can provide security in dealing with technologies, which consequently could have an effect on a reduced perception of technostress in online shoppers.

\section{References}

[1] Arnold, M.J., and K.E. Reynolds, "Hedonic shopping motivations", Journal of retailing 79(2), 2003, pp.77-95.

[2] Lee, E., G.P. Moschis, and A. Mathur, "A study of life events and changes in patronage preferences", Journal of Business Research, 54(1), 2001, pp. 25-38.

[3] Everard, A., and D.F. Galletta, "How presentation flaws affect perceived site quality, trust, and intention to purchase from an online store", Journal of Management Information Systems, 22(3), 2005, pp. 56-95.

[4] Jarvenpaa, S.L., N. Tractinsky, and L. Saarinen, "Consumer trust in an Internet store: A cross-cultural validation", Journal of Computer-Mediated Communication, 5(2), 1999, JCMC526.

[5] Moody, G.D., D.F. Galletta, and P.G. Lowry, "When trust and distrust collide online: The engenderment and role of consumer ambivalence in online consumer behavior", Electronic Commerce Research and Applications, 13(4), 2014, pp. 266-282.

[6] Tung, L.L., Y. Xu, and F.B. Tan, "Attributes of web site usability: a study of web users with the repertory grid technique", International Journal of Electronic Commerce, 13(4), 2009, pp. 97-126.

[7] Lazarus, R.S., and S. Folkman, Stress, appraisal, and coping, Springer publishing company, New York, 1984.

[8] Lazarus, R.S. and S. Folkman, "Transactional theory and research on emotions and coping", European Journal of Personality, 1(3), 1987, pp. 141-169.

[9] Riedl, R., H. Kindermann, A. Auinger, and A. Javor, "Technostress from a neurobiological perspective", Business \& Information Systems Engineering, 4(2), 2012, pp. 61-69.

[10] Ragu-Nathan, T.S., M. Tarafdar, B.S. Ragu-Nathan, and $\mathrm{Q} . \mathrm{Tu}$, "The consequences of technostress for end users in organizations: Conceptual development and empirical validation", Information Systems Research 19(4), 2008, pp. 417-433.

[11] Tarafdar, M., C.L. Cooper, and J.-F. Stich, "The technostress trifecta-techno eustress, techno distress and design: Theoretical directions and an agenda for 
research", Information Systems Journal, 29(1), 2019, pp. 6-42.

[12] Weinert, C., C. Maier, S. Laumer, and T. Weitzel, "How do users respond to technostress? An empirical analysis of proactive and reactive coping", HICSS 2019: Proceedings of the 52nd Hawaii International Conference on System Science, 2019, pp. 5103-5112.

[13] Pirkkalainen, H., M. Salo, M. Tarafdar, and M. Makkonen, "Deliberate or instinctive? Proactive and reactive coping for technostress", Journal of Management Information Systems, 36(4), 2019, pp. 1179-1212.

[14] Chen, J.V., A. Tran, and T. Nguyen, "Understanding the discontinuance behavior of mobile shoppers as a consequence of technostress: An application of the stresscoping theory", Computers in Human Behavior, 95, 2019, pp. 83-93.

[15] Duhachek, A., and D. Iacobucci, "Consumer personality and coping: Testing rival theories of process", Journal of Consumer Psychology, 15(1), 2005, pp. 52-63.

[16] Lazarus, R.S., Psychological stress and the coping process, McGraw-Hill, New York, USA, 1966.

[17] Moody, G.D., and D.F. Galletta, "Lost in cyberspace: The impact of information scent and time constraints on stress, performance, and attitudes online", Journal of Management Information Systems, 32(1), 2015, pp. 192224.

[18] Suri, R., and K.B. Monroe, "The effects of time constraints on consumers' judgments of prices and products", Journal of Consumer Research, 30(1), 2003, pp. 92-104.

[19] Keinan, G., "Decision making under stress: scanning of alternatives under controllable and uncontrollable threats", Journal of Personality and Social Psychology 52(3), 1987, p. 639-644.

[20] Carver, C.S., M.F. Scheier, and J.K. Weintraub, "Assessing coping strategies: a theoretically based approach", Journal of Personality and Social psychology 56(2), 1989, pp. 267-283.

[21] Kraft, F.B., D. Maity, and S. Porter, "The salesperson wellness lifestyle, coping with stress and the reduction of turnover", Journal of Business \& Industrial Marketing, 2019, pp. 347-359.

[22] Gefen, D., E. Karahanna, and D.W. Straub, "Trust and TAM in online shopping: An integrated model", MIS quarterly, 2003, pp. 51-90.

[23] Gefen, D., and D.W. Straub, "Consumer trust in B2C eCommerce and the importance of social presence: experiments in e-Products and e-Services", Omega, 32(6), 2004, pp. 407-424.

[24] Oliveira, T., M. Alhinho, P. Rita, and G. Dhillon "Modelling and testing consumer trust dimensions in ecommerce", Computers in Human Behavior, 71, 2017, pp. 153-164.

[25] Sujan, M., H. Sujan, J.R. Bettman, and T.M. Verhallen, "Sources of consumers' stress and their coping strategies", ACR European Advances, 1999, pp. 182-187.

[26] Dhar, R., and S.M. Nowlis, "The effect of time pressure on consumer choice deferral", Journal of Consumer Research, 25(4), 1999, pp. 369-384.
[27] Luce, M.F., J.W. Payne, and J.R. Bettman, "Emotional trade-off difficulty and choice", Journal of Marketing Research, 36(2), 1999, pp. 143-159.

[28] Boss, S.R., D.F. Galletta, P.B. Lowry, G.D. Moody, and P. Polak, "What do systems users have to fear? Using fear appeals to engender threats and fear that motivate protective security behaviors", MIS Quarterly, 39(4), 2015, pp. 837-864.

[29] Tarafdar, M., Q. Tu, and T.S. Ragu-Nathan. "Impact of technostress on end-user satisfaction and performance", Journal of Management Information Systems, 27(3), 2010, pp. 303-334.

[30] Cui, G., W. Bao, and T.S. Chan. "Consumers' adoption of new technology products: the role of coping strategies", Journal of Consumer Marketing, 26(2), 2009, pp. 110120.

[31] Tarafdar, M., Q. Tu, B.S. Ragu-Nathan, and T.S. RaguNathan, "The impact of technostress on role stress and productivity", Journal of Management Information Systems 24(1), 2007, pp. 301-328.

[32] Ayyagari, R., V. Grover, and R. Purvis, "Technostress: Technological antecedents and implications", MIS Quarterly, 2011, pp. 831-858.

[33] Dolan, S., and T. Aharon, "Implementing computer-based automation in the office: A study of experienced stress", Journal of Organizational Behavior, 1988, pp. 183-187.

[34] Zuboff, S. In the Age of the Smart Machine: The Future of Work and Power, Basic Books, New York, 1988.

[35] Maier, C., S. Laumer, and A. Eckhardt, "Information technology as daily stressor: Pinning down the causes of burnout", Journal of Business Economics, 85, 2015, pp. 349-387.

[36] La Torre, G., A. Esposito, I. Sciarra, and M. Chiappetta, "Definition, symptoms and risk of techno-stress: a systematic review", International Archives of Occupational and Environmental Health, 92(1), 2019, pp. 13-35.

[37] Maier, C., S. Laumer, A. Eckhardt, and T. Weitzel, "Online social networks as a source and symbol of stress: an empirical analysis", ICIS 2012: Proceedings of the 33rd International Conference on Information Systems, 2012.

[38] La Torre, G., V. De Leonardis, and M. Chiappetta, "Technostress: how does it affect the productivity and life of an individual? Results of an observational study", Public Health, 189, 2020, pp. 60-65.

[39] Maier, C., S. Laumer, C. Weinert, and T. Weitzel, "The effects of technostress and switching stress on discontinued use of social networking services: a study of Facebook use", Information Systems Journal, 25(3), 2015, pp. 275-308.

[40] Salo, M., H. Pirkkalainen, and T. Koskelainen, "Technostress and social networking services: Explaining users' concentration, sleep, identity, and social relation problems", Information Systems Journal, 29(2), 2019, pp. 408-435.

[41] Tarafdar, M., C. Maier, S. Laumer, and T. Weitzel, "Explaining the link between technostress and technology addiction for social networking sites: A study of distraction as a coping behavior", Information Systems Journal, 30(1), 2020, pp. 96-124. 
[42] Ram, S., and J.N. Sheth, "Consumer resistance to innovations: the marketing problem and its solutions", Journal of Consumer Marketing, 1989, pp. 5-14.

[43] Grummeck-Braamt, J.-V., I. Nastjuk, A. Najmaei, and M. Adam, "A Bibliometric Review of Technostress: Historical Roots, Evolution and Central Publications of a Growing Research Field", Proceedings of the 54th Hawaii International Conference on System Sciences, 2021, pp. 6621-6630.

[44] Green, D.T., and J.M. Pearson, "Integrating website usability with the electronic commerce acceptance model", Behaviour \& Information Technology, 30(2), 2011, pp. 181-199.

[45] Qureshi, I., Y. Fang, E. Ramsey, P. McCole, P. Ibbotson, and D. Compeau, "Understanding online customer repurchasing intention and the mediating role of trust-an empirical investigation in two developed countries", European Journal of Information Systems 18(3), 2009), pp. 205-222.

[46] Nielsen, J., Designing web usability, New Riders, Indianapolis, USA, 2000.

[47] Lowry, P.B., A. Vance, G.D. Moody, B. Beckman, and A. Read, "Explaining and predicting the impact of branding alliances and web site quality on initial consumer trust of e-commerce web sites", Journal of Management Information Systems, 24(4), 2008, pp. 199224.

[48] Coulter, K.S., M. Brengman, and F.P. Karimov, "The effect of web communities on consumers' initial trust in B2C e-commerce websites", Management Research Review, 35(9), 2012, pp.791-817.

[49] Fuentes, C., and A. Svingstedt, "Mobile phones and the practice of shopping: A study of how young adults use smartphones to shop", Journal of Retailing and Consumer Services, 38, 2017, pp. 137-146.

[50] Van der Heijden, H., T. Verhagen, and M. Creemers, "Understanding online purchase intentions: contributions from technology and trust perspectives", European Journal of Information Systems, 12(1), 2003, pp. 41-48.

[51] Zhao, X., Q. Xia, and W. Huang, "Impact of technostress on productivity from the theoretical perspective of appraisal and coping processes", Information \& Management, 57(8), 2020, 1-11.

[52] Lu, Y., Y. Lu, and B. Wang, "Effects of dissatisfaction on customer repurchase decisions in e-commerce-an emotion-based perspective", Journal of Electronic Commerce Research, 13(3), 2012, pp. 224-237.

[53] Gan, C., and H. Li, "Understanding the effects of gratifications on the continuance intention to use WeChat in China: A perspective on uses and gratifications", Computers in Human Behavior, 78, 2018, pp. 306-315.

[54] Aaker, D.A., V. Kumar, G.S. Day and R.P. Leone, "Marketing research", Hoboken: Wiley, 2011.

[55] Parasuraman, A., D. Grewal, and R. Krishnan, "Marketing Research", Boston: George T., 2007.

[56] Statista, "Anteil der Internetnutzer, die in den letzten drei Monaten Einkäufe und Bestellungen über das Internet getätigt haben, nach Altersgruppen in Deutschland im Jahr 2020", URL: https://de.statista.com/statistik/daten/studie/28542/umfra ge/nutzer-von-e-commerce-je-altersgruppe-im-jahr2007/, 2020.

[57] Bagozzi, R. P., and Y. Yi, "On the evaluation of structural equation models", Journal of the Academy of Marketing Science, 16(1), 1988, pp. 74-94.

[58] Schreiber, J.B., A. Nora, F.K. Stage, E.A. Barlow, and J. King, "Reporting structural equation modeling and confirmatory factor analysis results: a review", Journal of Educational Research, 99(6), 2006, pp. 323-338.

[59] Nunnally, J., "Psychometric Theory", McGraw-Hill, New York, USA, 1978.

[60] Fornell, C., and D.F. Larcker, "Evaluating structural equation models with unobservable variables and measurement error", Journal of Marketing Research, 18(1), 1981, pp. 39-50.

[61] Hayes, A.F., "Introduction to mediation, moderation, and conditional process analysis: A regression-based approach", 2nd edition, Guilford press, New York, USA, 2018.

[62] Preacher, K. J., and A. F. Hayes, "Asymptotic and resampling strategies for assessing and comparing indirect effects in multiple mediator models", Behavior Research Methods, 40(3), 2008, pp. 879-891.

[63] Pirkkalainen, H., M. Salo, M. Makkonen, and M. Tarafdar, "Coping with Technostress: When Emotional Responses Fail", ICIS 2017: Proceedings of the 38th International Conference on Information Systems, 2017, pp. 1-17.

[64] Moody, G.D., D.F. Galletta, and B.K. Dunn, "Which phish get caught? An exploratory study of individuals' susceptibility to phishing", European Journal of Information Systems, 26(6), 2017, pp. 564-584.

[65] Holzwarth, M., C. Janiszewski, and M.M. Neumann, "The influence of avatars on online consumer shopping behavior", Journal of Marketing, 70(4), 2006, pp. 19-36.

[66] Wölfl, S., and J. Feste, "Do you trust me? Facial widthto-height ratio of website avatars and intention to purchase from online store", ICIS 2018: Proceedings of the 39th International Conference on Information Systems, 2018.

[67] Wölfl, S., J. Feste, and L. Peters, "The perfect match: Nonhuman-type avatar-online store fit and intention to purchase", AMCIS 2019: Proceedings of the 25th Conference on Information Systems, 2019.

[68] Liew, T.W., S.M. Tan, and H. Ismail, "Exploring the effects of non-interactive talking avatar on social presence, credibility, trust, and patronage intention in an e-commerce website", Human Centric Computing and Information Sciences, 7(1), 2017, pp. 1-21.

[69] Qiu, L., and I. Benbasat, "Evaluating anthropomorphic product recommendation agents: a social relationship perspective to designing information systems", Journal of Management Information Systems, 25(4), 2009, pp. 145182. 